\title{
TRATAMENTO DE EFLUENTES INDUSTRIAIS POR PROCESSOS OXIDATIVOS NA PRESENÇA DE OZÔNIO
}

\section{Edna Almeida*, Márcia Regina Assalin e Maria Aparecida Rosa}

Departamento de Físico-Química, Instituto de Química, Universidade Estadual de Campinas, CP 6154, 13084-971 Campinas - SP Nelson Durán

Núcleo de Ciências Ambientais, Universidade de Mogi das Cruzes, Mogi das Cruzes -SP

Recebido em 5/8/03; aceito em 16/2/04; publicado na web em 6/7/04

\begin{abstract}
WASTEWATER TREATMENT BY OXIDATION WITH OZONE. A large variety of organic and inorganic compounds may be found in wastewater which can contribute to environmental contamination. Oxidation processes with ozone $\left(\mathrm{O}_{3} ; \mathrm{O}_{3} / \mathrm{UV}_{3} \mathrm{O}_{3} / \mathrm{H}_{2} \mathrm{O}_{2}\right.$; $\mathrm{O}_{3} / \mathrm{TiO}_{2} ; \mathrm{O}_{3} / \mathrm{Mn}^{+2}$ ) and the use of ozone in the pre- or post-treatment of wastewater combined with biological processes has been extensively studied for the treatment of effluents. The aim of this work was to evaluate the potential of the ozonation process in the treatment of several industrial wastewaters, namely effluents from paper mills, and textile, whey (dairy industry), pharmaceutic sand pesticides plants.
\end{abstract}

Keywords: ozonation process; treatment; industrial effluents.

\section{INTRODUÇÃO}

Muitos estudos têm sido realizados com intuito de desenvolver tecnologias capazes de minimizar o volume e a toxicidade dos efluentes industriais, de forma a permitir não somente a remoção de substâncias contaminantes, mas também sua completa mineralização. A toxicidade associada aos efluentes industriais pode estar intimamente relacionada com a presença de compostos recalcitrantes $^{1}$.

Compostos recalcitrantes ou refratários não são biodegradados pelos organismos normalmente presentes em sistemas biológicos de tratamento, nos usuais tempos de retenção hidráulica aplicados sendo, então, lançados nos corpos aquáticos receptores. Devido ao efeito de acumulação, podem atingir concentrações superiores à dose letal de alguns organismos, como invertebrados e peixes, levando à ocorrência de morte. Além disso, os efeitos cancerígenos e mutagênicos eventualmente podem ser observados em humanos como resultado da bioacumulação ao longo da cadeia alimentar ${ }^{2}$.

Ozônio e os processos oxidativos avançados (POAs) relacionados, tais como $\mathrm{O}_{3} / \mathrm{UV}, \mathrm{O}_{3} / \mathrm{H}_{2} \mathrm{O}_{2} \mathrm{O}_{3} / \mathrm{TiO}_{2}$, têm servido como alternativa para o tratamento de tais compostos, mostrando-se bastante eficazes no processo de descontaminação ambiental ${ }^{3,4}$.

O ozônio é capaz de reagir com uma numerosa classe de compostos orgânicos, devido, principalmente, ao seu elevado potencial de oxidação $\left(\mathrm{E}^{0}=2,08 \mathrm{~V}\right)$, superior ao de compostos reconhecidamente oxidantes, como $\mathrm{H}_{2} \mathrm{O}_{2}$ e o próprio cloro ${ }^{5,6}$. No entanto, muitos compostos orgânicos como os organoclorados reagem lentamente com o ozônio molecular. Contudo, em determinadas condições o ozônio leva à formação de radicais hidroxilas $(\cdot \mathrm{OH})$, cujo potencial de oxidação é ainda mais elevado $\left(\mathrm{E}^{0}=3,06 \mathrm{~V}\right)$, podendo ser mais efetivo no tratamento de certos compostos recalcitrantes. Os processos que implicam na formação do radical hidroxila são denominados Processos Oxidativos Avançados (POAs) ${ }^{3}$.

Devido à instabilidade do ozônio, aproximadamente $3 \mathrm{~s}$ na fase gasosa, o que impede sua armazenagem, torna-se necessária sua geração in situ ${ }^{6}$. Ozônio pode ser produzido por três diferentes técni-

\footnotetext{
*e-mail: edna-almeida@iqm.unicamp.br
}

cas: exposição do $\mathrm{O}_{2}$ à luz ultravioleta, eletrólise do ácido perclórico e descarga eletroquímica? ${ }^{7}$.

Dentre os diferentes processos de produção apresentados, o que utiliza descarga elétrica (também conhecido por efeito corona) é o mais utilizado pela maioria dos ozonizadores comerciais, principalmente pelo fato de se obter maior taxa de conversão do oxigênio em ozônio. Neste método, o ozônio é gerado pela passagem de ar ou oxigênio puro entre dois eletrodos submetidos a uma elevada diferença de potencial (aproximadamente $10 \mathrm{kV}$ ), conforme Equações 1 e 2 . O rendimento deste processo varia entre 1 e $4 \%(\mathrm{~m} / \mathrm{m})$ e entre 6 e $14 \%(\mathrm{~m} / \mathrm{m})$ para sistemas alimentados por ar e oxigênio puro, respectivamente ${ }^{5,7,8}$.

$\mathrm{O}_{2} \rightarrow \mathrm{O}^{*}+\mathrm{O}^{*}$
$\mathrm{O}^{*}+\mathrm{O}_{2} \rightarrow \mathrm{O}_{3}$

Ozônio é instável em água. A decomposição do ozônio em águas naturais é caracterizada por uma rápida diminuição da concentração inicial do ozônio, seguida de uma segunda fase na qual a concentração de ozônio diminui segundo uma cinética de primeira ordem ${ }^{9}$, sendo que o principal produto de decomposição do ozônio é o radical hidroxila $\cdot \mathrm{OH}$

Dependendo da qualidade do meio em que se encontra, o tempo de meia vida do ozônio varia de alguns segundos até horas. A estabilidade do ozônio no meio depende de diversos fatores, dentre eles, o $\mathrm{pH}$ merece especial atenção, uma vez que os íons hidroxila iniciam o processo de decomposição do ozônio, como mostrado nas Equações 3 e 49 .

$\mathrm{O}_{3}+\mathrm{OH}^{-} \rightarrow \mathrm{HO}_{2}^{-}+\mathrm{O}_{2}$

$\mathrm{O}_{3}+\mathrm{HO}_{2}^{-} \rightarrow{ }^{\cdot} \mathrm{OH}+\mathrm{O}_{2}^{-\cdot}+\mathrm{O}_{2}$

De acordo com as Equações 3 e 4, a decomposição do ozônio pode ser acelerada pelo aumento do $\mathrm{pH}$ ou pela adição de peróxido de hidrogênio. Desta maneira, a oxidação de compostos orgânicos e inorgânicos durante a ozonização pode ocorrer via ozônio molecular (reação direta - predominante em meio ácido) ou radical hidroxila (reação indireta - predominante em meio alcalino), embora na prática haja contribuição dos dois mecanismos ${ }^{9}$. A reação direta (ataque 
eletrofílico pelo ozônio molecular) é atribuída a compostos que contêm ligações do tipo $\mathrm{C}=\mathrm{C}$, grupos funcionais específicos $\left(\mathrm{OH}, \mathrm{CH}_{3}\right.$, $\left.\mathrm{OCH}_{3}\right)$ e átomos que apresentam densidade de carga negativa $(\mathrm{N}, \mathrm{P}$, $\mathrm{O}$ e S). A reação indireta é não seletiva, sendo capaz de promover um ataque a compostos orgânicos $10^{6}-10^{9}$ vezes mais rápido que conhecidos agentes oxidantes, como o $\mathrm{H}_{2} \mathrm{O}_{2}$ e o próprio $\mathrm{O}_{3}^{2,3,10}$. Entretanto, cada uma das espécies oxidantes assume diferentes graus de importância, em função da aplicação específica do ozônio 9 . Enquanto processos de desinfecção ocorrem predominantemente via ozônio molecular, processos de oxidação podem ocorrer tanto por meio do ozônio molecular como do radical hidroxila ${ }^{3,9}$.

Os recentes avanços nos sistemas de geração de ozônio têm diminuído a energia requerida para sua produção, resultando numa considerável redução nos custos envolvidos para sua aplicação, o que vem tornando a utilização deste processo bastante atrativa ${ }^{10}$

Além da ozonização via $\mathrm{O}_{3}$ molecular (reação direta - meio ácido) e via radical hidroxila (reação indireta - meio alcalino) outras possibilidades de aplicação do ozônio na remediação de efluentes estão disponíveis na literatura. Ozônio combinado com luz ultravioleta $\left(\mathrm{O}_{3} / \mathrm{UV}\right)$, com peróxido de hidrogênio $\left(\mathrm{O}_{3} / \mathrm{H}_{2} \mathrm{O}_{2}\right)$ ou uma combinação destes $\left(\mathrm{O}_{3} / \mathrm{UV} / \mathrm{H}_{2} \mathrm{O}_{2}\right)$, além de $\mathrm{O}_{3}$ /ultrasom e $\mathrm{O}_{3} / \mathrm{TiO}_{2}$, apresentam resultados efetivos na remediação de alguns efluentes industriais. Tecnologias emergentes, como a ozonização catalítica e a nanocatálise heterogênea utilizando ozônio, mostram-se bastante promissoras, além de constituírem a tendência atual dos processos de ozonização ${ }^{10-14}$.

Este trabalho tem como objetivo divulgar as principais tendências de aplicação de diferentes processos de ozonização $\left(\mathrm{O}_{3} ; \mathrm{O}_{3} / \mathrm{UV}\right.$; $\mathrm{O}_{3} / \mathrm{H}_{2} \mathrm{O}_{2} ; \mathrm{O}_{3} / \mathrm{TiO}_{2} ; \mathrm{O}_{3} / \mathrm{Mn}^{+2}$ ) além de processos combinados (ozônio - biológico) no tratamento de diferentes tipos de efluentes industriais, que estejam associados a problemas de contaminação ambiental devido à carga orgânica, cor ou à presença de compostos recalcitrantes e persistentes, além da toxicidade. Cinco aplicações importantes, tratamento de efluentes de papel e celulose, têxtil, queijeiro e efluentes contaminados com compostos farmacêuticos e pesticidas, são discutidas abaixo.

\section{OZONIZAÇÃO DE EFLUENTES INDUSTRIAIS}

\section{Efluente papeleiro}

A indústria papeleira tem uma grande importância para a economia da América do Sul devido à enorme disponibilidade de recursos florestais, sendo o Brasil e o Chile os maiores produtores de celulose da região. No Brasil, usa-se preferencialmente madeira de Eucalyptus grandis, com uma produção ao redor de 6 milhões de toneladas de polpa por ano ${ }^{15,16}$.

Além de sua indiscutível importância econômica, as empresas de papel e celulose apresentam um elevado potencial de contaminação ambiental, não somente pela presença de compostos refratários, mas também pelo elevado volume de efluente gerado $\left(80 \mathrm{~m}^{3} \mathrm{de}\right.$ água/ tonelada de polpa gerada), o que implica num grande volume de efluente a ser tratado antes de seu lançamento nos corpos aquáticos receptores ${ }^{17}$.

Numa primeira etapa de produção de papel ocorre a deslignificação da madeira (polpação), seguida pela etapa de branqueio da polpa. Ambas as etapas geram um grande volume de efluente fortemente colorido, devido principalmente à presença da lignina e compostos organoclorados de alto e baixo pesos moleculares ${ }^{10}$.

Embora o volume de efluente gerado durante a etapa de branqueamento seja significativamente menor (cerca de $10 \mathrm{~m}^{3}$ por tonelada de polpa), é nesta etapa que se formam os compostos mais deletérios para o meio ambiente. Durante o processo convencional de branqueamento, utiliza-se cloro elementar (numa proporção de $45 \mathrm{~kg}$ de cloro por $\mathrm{t}$ de polpa) para a remoção da lignina residual presente nas fibras celulósicas, sendo gerada uma enorme variedade e quantidade de substâncias organocloradas ( 2 a 1,5 kg por $\mathrm{t}$ de polpa) recalcitrantes e altamente tóxicas. Alguns compostos tipicamente encontrados no efluente papeleiro são mostrados na Figura $1^{10,18-22}$.
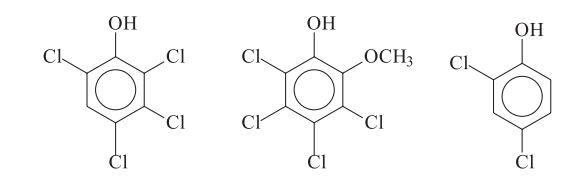

2,3,4,6-tetraclorofenol

tetracloroguaiacol

2,4-diclorofenol

Figura 1. Exemplos de compostos organoclorados presentes no efluente papeleiro

Parte deste problema tem sido resolvido pelas modificações introduzidas pelas indústrias de papel e celulose nos procedimentos de branqueamento da polpa, sendo a principal delas a substituição total ou parcial do cloro elementar, originando os processos denominados "Total Chlorine Free (TCF)" e "Elementary Chlorine Free (ECF)". A utilização de tais processos não eliminou totalmente o impacto ambiental do efluente, no primeiro caso, pela necessidade de se adicionar grandes quantidades de quelantes como EDTA, que geram um novo problema de contaminação ambiental e, no segundo, pela persistência de alguns compostos organoclorados, de alto e baixo pesos moleculares, que podem estar associados à toxicidade crônica e aguda da biota aquática ${ }^{16,23,24}$.

Estudos demonstraram que a toxicidade dos efluentes da indústria papeleira não é uma função exclusiva do teor de compostos organoclorados, já que mais de 300 compostos orgânicos têm sido detectados em efluentes de branqueamento, alguns de reconhecido efeito tóxico e/ou genotóxico ${ }^{25,26}$.

A aplicação do processo de ozonização na remediação do efluente papeleiro tem se mostrado bastante eficiente na descoloração do efluente, na oxidação de compostos refratários, na remoção da toxicidade e no aumento da biodegradabilidade do efluente. É capaz de converter compostos de alto peso molecular em ácidos orgânicos de reduzida massa molar, além de promover alterações na estrutura química da molécula ${ }^{3,10,21,27,28}$.

Freire et al..$^{21}$ aplicaram o processo de ozonização no tratamento do efluente papeleiro via reação direta (ozônio molecular) e indireta (radical hidroxila). Ambos os processos foram comparados quanto à eficiência de remoção de carbono orgânico total (COT), fenóis totais e cor do efluente. O processo em que a reação indireta estava presente foi mais efetivo, tanto na descoloração quanto na remoção de fenóis totais, apresentando uma cinética reacional 1,8 e 2,5 vezes mais rápida, respectivamente. A descoloração do efluente está diretamente associada com a degradação da lignina, que pode levar à formação de ácidos orgânicos (como mucônico, maléico e oxálico) em pH fortemente alcalino, devido aos radicais ${ }^{\circ} \mathrm{OH}$ fortemente oxidantes, embora a completa mineralização possa não ser atingida ${ }^{17}$. É importante salientar que a reação indireta é favorecida em meios alcalinos, não sendo necessário, neste caso, ajuste do $\mathrm{pH}$ do efluente, já que seu pH original é aproximadamente 11. Embora o consumo de ozônio no processo $\mathrm{O}_{3} / \mathrm{pH} 11$ ter sido superior ao do processo $\mathrm{O}_{3} / \mathrm{pH} 3$, a eficiência de remoção de COT foi inferior a $10 \%$ para ambos os processos, indicando deficiência no processo de mineralização do efluente, seja por via direta ou indireta ${ }^{10,29}$. Zhou e Smith $^{28}$ obtiveram resultados similares para o tratamento do efluente papeleiro ( $\mathrm{pH} \cong 7)$ por ozônio. Para as diferentes doses de ozônio aplicadas (30 a $240 \mathrm{mg} \mathrm{L}^{-1}$ ), o ozônio mostrou-se bastante efetivo na remoção de cor e dos halogênios orgânicos adsorvíveis (AOX). As remoções 
da demanda química de oxigênio (DQO) e COT foram pouco significativas, indicando que o ozônio foi capaz de degradar os grupos funcionais responsáveis pela cor do efluente, embora não tenha sido possível atingir um elevado grau de mineralização, mesmo utilizando elevadas doses de ozônio, num meio em que ambos os mecanismos contribuem para o processo de degradação ${ }^{28}$.

A ozonização via radical hidroxila $\left(\mathrm{O}_{3} / \mathrm{pH} 11\right)$ foi aplicada no tratamento do efluente papeleiro por Freire et al. ${ }^{21}$, com o intuito de otimizar o processo quanto à dose de ozônio aplicada e ao tempo de tratamento necessário para obtenção da melhor eficiência de remoção de cor, fenóis totais, COT, além da toxicidade aguda (determinada por meio de testes respirométricos frente à bactéria Escherichia coli $\left.^{30}\right)$. Após $60 \mathrm{~min}$ de tratamento, correspondendo a uma dose de 200 mg L ${ }^{-1}$, obteve-se uma eficiência de 35 e $70 \%$ na descoloração e remoção de fenóis totais, confirmando a eficiência do ozônio em degradar compostos fenólicos. Após este período, o consumo de ozônio no meio reacional foi bastante reduzido, e o tratamento pode ser interrompido neste ponto. A toxicidade do efluente foi reduzida em $70 \%$, sendo que esta redução é uma função da carga de ozônio e do período de tratamento ${ }^{20}$. Testes de toxicidade são importantes, quando processos de ozonização são aplicados, porque os compostos tóxicos, como cetonas, ácidos orgânicos e aldeídos, podem ser gerados durante o tratamento com ozônio ${ }^{21,30-32}$.

Assalin e colaboradores ${ }^{33}$ estudaram a influência do $\mathrm{pH}$ inicial do efluente no processo de ozonização (10 e 12) para o tratamento do efluente papeleiro. A ozonização em meio ácido não foi estudada devido aos resultados insatisfatórios encontrados na literatura para este tipo de efluente ${ }^{11}$. Foi verificado que a cinética reacional é seriamente influenciada pelo $\mathrm{pH}$. Para a ozonização realizada em pH 10, não foi verificado consumo de ozônio após $2 \mathrm{~h}$ de tratamento, enquanto que em $\mathrm{pH} \mathrm{12,} \mathrm{o} \mathrm{consumo} \mathrm{de} \mathrm{ozônio} \mathrm{foi} \mathrm{verificado} \mathrm{mesmo}$ após $5 \mathrm{~h}$ de tratamento. Desta forma, a concentração de íons hidroxila pode afetar significativamente a cinética reacional nos processos de ozonização $0^{33,34}$

Perez et al. ${ }^{35}$ estudaram a degradação da matéria orgânica presente no efluente papeleiro Kraft $\mathrm{E}_{1}$ pela aplicação de diversos processos oxidativos avançados, entre eles, ozônio e $\mathrm{O}_{3} / \mathrm{UV}$. Os custos dos processos estudados foram calculados em função de unidade de COT removido, sendo que o processo $\mathrm{O}_{3} / \mathrm{UV}$ foi mais efetivo na redução de COT, além do custo ter sido reduzido em $25 \%{ }^{35}$.

Freire et al. ${ }^{10}$ compararam a eficiência dos processos oxidativos avançados (POAs) $\mathrm{O}_{3} / \mathrm{pH} 11, \mathrm{O}_{3} / \mathrm{pH}_{1} / \mathrm{H}_{2} \mathrm{O}_{2}$ e $\mathrm{O}_{3} / \mathrm{pH} 11 / \mathrm{UV}$, em termos de índice de oxidação (IO), definido como a razão entre a quantidade de ozônio consumido e a porcentagem de remoção de cor, fenóis totais ou COT, na remediação do efluente papeleiro. Um baixo valor de IO indica intensa utilização do ozônio durante o processo de oxidação e maior eficiência de remoção. Os processos $\mathrm{O}_{3} / \mathrm{pH}$ 11 e $\mathrm{O}_{3} / \mathrm{pH} 11 / \mathrm{UV}$ utilizaram menor dose de ozônio para uma efetiva remoção dos parâmetros estudados. A influência da irradiação UV foi relevante somente para a descoloração do efluente, uma vez que apresentou IO menor que dos demais processos ${ }^{10}$.

Desta forma, a ozonização do efluente papeleiro, preferencialmente em meio alcalino, é uma tecnologia bastante eficiente na remoção de cor, fenóis totais e outros compostos recalcitrantes, além da toxicidade. Entretanto, por si só o ozônio não é capaz de atingir um elevado grau de mineralização do efluente, o que é mostrado pelas pequenas taxas de remoção de COT apresentadas. No entanto, é indiscutível que ocorre alguma alteração na estrutura química dos compostos, uma vez que o aumento de biodegradabilidade é observado. A utilização de outros POAs relacionados com ozônio, como $\mathrm{O}_{3} / \mathrm{pH}_{1} 1 / \mathrm{H}_{2} \mathrm{O}_{2}$ e $\mathrm{O}_{3} / \mathrm{pH} 11 / \mathrm{UV}$ também é viável para o tratamento deste efluente, entretanto, o grau de mineralização atingido por estes processos também não é satisfatório ${ }^{10}$.

\section{Efluente têxtil}

A problemática ambiental associada ao efluente têxtil é bastante conhecida. Devido à sua própria natureza, a presença dos corantes é facilmente detectada, sendo visíveis mesmo em concentrações tão baixas como $1 \mathrm{mg} \mathrm{L}^{-1}$. Quando lançados nos corpos aquáticos receptores, mesmo quantidades reduzidas podem alterar a coloração natural dos rios, resultando em graves problemas estéticos além de reduzir alguns processos fotossintéticos ${ }^{36,37}$. Apresentam composição química variada, baixa degradabilidade por processos biológicos, elevada DQO, além da presença de compostos recalcitrantes que podem estar associados à toxicidade crônica e aguda ${ }^{38,39}$.

Os corantes utilizados pela indústria têxtil podem ser classificados de acordo com sua estrutura química (antraquinona, azo, etc.) ou pelo método de fixação à fibra têxtil (reativos, diretos, azóicos, ácidos, dispersos, etc.) ${ }^{37}$. A Figura 2 apresenta algumas estruturas típicas dos corantes utilizados pela indústria têxtil.
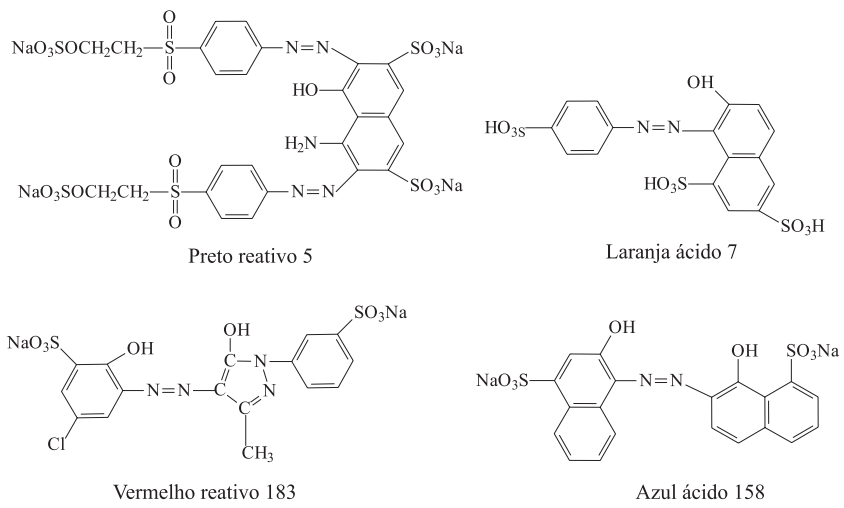

Figura 2. Estruturas típicas de alguns corantes utilizados na indústria têxtil

Pesquisas referentes ao tratamento do efluente têxtil freqüentemente enfocam os corantes reativos por três razões principais: representam aproximadamente 20 a $30 \%$ de todos os corantes utilizados; cerca de $30 \%$ do corante utilizado é transformado em resíduo, devido à baixa fixação em fibras celulósicas e à baixa eficiência de remoção destes corantes pelos tratamentos biológicos convencionais $^{2,37,40}$.

Dentre os vários métodos que têm sido desenvolvidos para o tratamento deste efluente, o processo de ozonização tem sido sugerido na literatura recente como sendo um processo bastante promissor, devido à capacidade de descoloração e aumento da biodegradabilidade do efluente. Além disso, o fato do sistema não gerar resíduos sólidos (como no caso do lodo ativado) e ser de fácil instalação e operação torna sua aplicação ainda mais atrativa ${ }^{41,42}$.

Durante o processo de ozonização ocorre a descoloração do efluente devido à clivagem oxidativa dos grupos cromóforos, seja por via direta ou indireta ${ }^{41}$. A clivagem destas ligações duplas conjugadas e de outros grupos funcionais faz com que as moléculas percam a habilidade de absorver luz na região visível do espectro eletromagnético ${ }^{2}$.

Resultados provenientes de estudos de ozonização do efluente têxtil, em escala de laboratório, mostraram que a redução de cor é bastante eficiente, contribuindo significativamente para o reuso da água na própria planta de tratamento podendo, assim, chegar à descarga zero ${ }^{41}$.

Estudos realizados por Sevimli e Kinaci ${ }^{41}$ demonstraram que a ozonização do efluente têxtil em meio alcalino removeu mais eficientemente a cor e a DQO do efluente que em meio ácido, embora a diferença não tenha sido tão significativa. A eficiência de descoloração aumentou de 68 para $75 \%$, enquanto que a remoção da DQO 
aumentou de 11 para $12 \%$, para meio ácido e alcalino, respectivamente. Isto foi concordante com o fato de não terem sido observadas diferenças significativas na dose de ozônio consumido ${ }^{41}$. Além disso, a ozonização também foi capaz de aumentar a biodegradabilidade do efluente (expressa como a razão DBO/DQO) de 0,58 para 0,62 e 0,75 , após tratamento com doses de ozônio correspondentes a 12 e $111 \mathrm{mg} \mathrm{L}^{-1} \mathrm{O}_{3}$, respectivamente ${ }^{41}$.

A elevada remoção de cor e a limitada remoção de matéria orgânica (expressa como COT e DQO) também foram observadas por Sevimli e Sarikaya ${ }^{42}$. Isto pode ser explicado pela capacidade do ozônio quebrar as duplas ligações dos compostos orgânicos, fazendo com que as moléculas percam a habilidade de absorver luz na região visível. Já a baixa remoção de COT é devida à oxidação incompleta dos compostos orgânicos, ou seja, o processo não atinge o grau de mineralização desejado ${ }^{42,43}$.

Sunder e Hempel ${ }^{11}$ utilizando $\mathrm{O}_{3} / \mathrm{H}_{2} \mathrm{O}_{2}$ obtiveram completa mineralização de tricloroeteno e percloroeteno. No entanto, o mesmo processo foi utilizado para a remediação de um efluente têxtil sintético e os resultados obtidos mostraram que a adição de $\mathrm{H}_{2} \mathrm{O}_{2}$ apresentou efeito desprezível na remoção da DQO, comparativamente à aplicação de ozônio somente ${ }^{12}$.

Sevimli e Kinaci ${ }^{41}$ compararam a eficiência do processo Fenton com a ozonização e do processo Fenton na degradação de corantes têxteis (corante reativo laranja e corante ácido vermelho). Ambos os processos foram efetivos na remoção de cor; no entanto, o processo Fenton removeu mais eficientemente a DQO do efluente, atingindo até $73 \%$, enquanto que para a ozonização, a máxima eficiência obtida foi de $17 \%$. O pH do efluente não afetou significativamente a eficiência da remoção de cor e DQO pelo processo de ozonização, enquanto que para o processo Fenton é um fator determinante ${ }^{36}$.

Pelos resultados encontrados na literatura ${ }^{38,41,44}$, o efeito do $\mathrm{pH}$ do efluente têxtil é menos significativo na eficiência do processo de ozonização, comparativamente ao efluente papeleiro. A composição do efluente parece ser o fator determinante para a eficiência do referido processo, independentemente da via de oxidação utilizada. Isto pode ser confirmado pelos resultados obtidos por Kunz et al..$^{38}$. O pH do meio influenciou na eficiência do processo de ozonização na remoção de cor e COT apenas para um dos corantes estudados (preto reativo 5). Resultados similares foram obtidos por Khraisheh ${ }^{44}$ no tratamento de corantes reativos pelo processo de ozonização em meio alcalino. Foram obtidos $50 \%$ de eficiência na remoção da DQO para soluções de Remazol Black B e somente $15 \%$ para soluções de Remazol red RB e Remazol Golden Yellow RNL, para as mesmas doses de ozônio consumido. Neste caso, a composição do efluente têxtil foi o fator determinante para a eficiência do processo.

\section{Efluente farmacêutico}

De maneira geral, a atividade farmacêutica pode ser classificada de acordo com o processo de fabricação utilizado, em fermentação, síntese química, extração e formulação ${ }^{45}$. Os efluentes gerados em cada um dos processos produtivos apresentam características distintas e quantidade variada ${ }^{45,46}$. São caracterizados por uma fração orgânica rapidamente biodegradável e compostos refratários, que não são removidos por tratamentos biológicos convencionais, como no caso da formulação de antibióticos, cujo efluente apresenta baixa biodegradabilidade ${ }^{45}$. Estudos recentes indicam que antibióticos, como os do grupo das penicilinas, podem exercer efeitos tóxicos a organismos aquáticos e até promover o desenvolvimento de cepas bacterianas multi-resistentes ${ }^{45}$.

Compostos refratários são removidos mais eficientemente por processos químicos de remediação. Neste contexto, o processo de ozonização mostrou ser uma alternativa bastante promissora para o tratamento de rejeitos farmacêuticos, constituídos por compostos refratários $^{45,46}$. Arslan-Alaton e Balcioglu ${ }^{46}$ ozonizaram o efluente proveniente de uma indústria farmacêutica, após ter sido submetido a um tratamento biológico (lodo ativado), em diferentes valores de $\mathrm{pH}$ (3 e 8). O tratamento biológico foi capaz de remover apenas 10\% da DQO do efluente após $4 \mathrm{~h}$ de tratamento, atingindo o máximo de remoção (41\%) após $48 \mathrm{~h}$ de tratamento. Isto indica que o efluente é parcialmente susceptível ao tratamento biológico, o que é concordante com a razão DBO/DQO obtida $(0,54)$. A pequena redução da absorbância em 254 e $280 \mathrm{~nm}$ indica que compostos aromáticos permaneceram no efluente biotratado. A ozonização deste efluente em pH 8 (reação indireta) resultou numa lenta e ineficiente remoção de DQO (inferior a $10 \%$ ) após 4 h de ozonização. Entretanto, a redução da absorbância a 254 e $280 \mathrm{~nm}$ foi de 57 e $71 \%$, respectivamente. Em meio ácido, compostos orgânicos, que absorvem na região ultravioleta do espectro eletromagnético, foram mais rapidamente removidos. Isto é devido ao ataque seletivo do ozônio aos compostos aromáticos e às duplas ligações dos compostos alifáticos ${ }^{46}$. Como já foi discutido anteriormente, o efeito do $\mathrm{pH}$ na eficiência de ozonização depende do tipo de poluente e do reagente oxidante $\left(\mathrm{O}_{3}\right.$ ou radical hidroxila $\left.\cdot \mathrm{OH}\right)$.

Segundo Ternes et al. ${ }^{47}$, a ozonização é um processo bastante efetivo na oxidação de produtos farmacêuticos. A aplicação de doses 10-15 mg L $\mathrm{m}^{-1}$ de ozônio por um período de $18 \mathrm{~min}$ a um efluente farmacêutico, proveniente de uma indústria germânica, contendo antibióticos $\left(0,34\right.$ a $\left.0,63 \mu \mathrm{g} \mathrm{L}^{-1}\right)$, foi suficiente para a completa remoção de tais compostos.

Zwiener e Frimmel ${ }^{48}$ selecionaram alguns compostos farmacêuticos típicos (Figura 3) e submeteram à ozonização, em pH 7, durante 10 min. Neste $\mathrm{pH}$, a reação via radical hidroxila não contribui significativamente para o processo de oxidação. Dentre os compostos estudados, apenas o diclofenaco foi degradado rapidamente, mostrando que o ozônio reage seletivamente, sendo o grupo amino, presente na estrutura da molécula, o centro reacional.

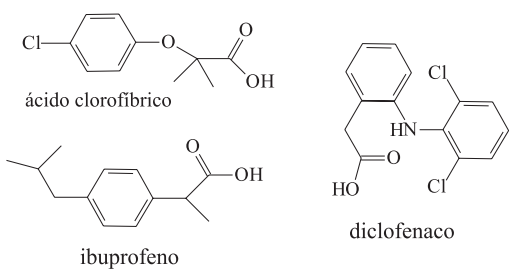

Figura 3. Alguns compostos típicos presentes no efluente farmacêutico

Balcioglu e Otker ${ }^{45}$ compararam o efeito do $\mathrm{pH}$ e da concentração de $\mathrm{H}_{2} \mathrm{O}_{2}$ no processo de ozonização, em termos de eficiência de remoção de DQO de efluentes farmacêuticos contendo alguns antibióticos de uso humano (identificados como grupo I e II) e veterinário, cujas estruturas estão apresentadas na Figura 4. O efeito do $\mathrm{pH}$ foi mais significativo para o caso do efluente que continha antibióticos de uso humano (grupo II), sendo a eficiência de remoção de DQO em pH 3 e 11 igual a 24 e $71 \%$, respectivamente. A combinação $\mathrm{O}_{3} / \mathrm{H}_{2} \mathrm{O}_{2}$ não apresentou vantagens significativas quanto à cinética de remoção de DQO em relação aos processos $\mathrm{O}_{3} / \mathrm{pH}$ neutro ou alcalino, exceto quando a concentração ideal de peróxido de hidrogênio foi utilizada. Concentrações de $\mathrm{H}_{2} \mathrm{O}_{2}$ superiores àquelas consideradas ideais ao processo implicam num acúmulo do oxidante no meio reacional, que passam a agir como supressores dos radicais hidroxilas, resultando numa diminuição da eficiência na remoção de $\mathrm{DQO}^{45}$.

A ozonização é um processo que apresenta grande potencial para remediação do efluente farmacêutico, devido à capacidade do processo em remover compostos refratários como os tipicamente encontrados neste efluente, no entanto a eficiência de remoção de COT é pequena. 


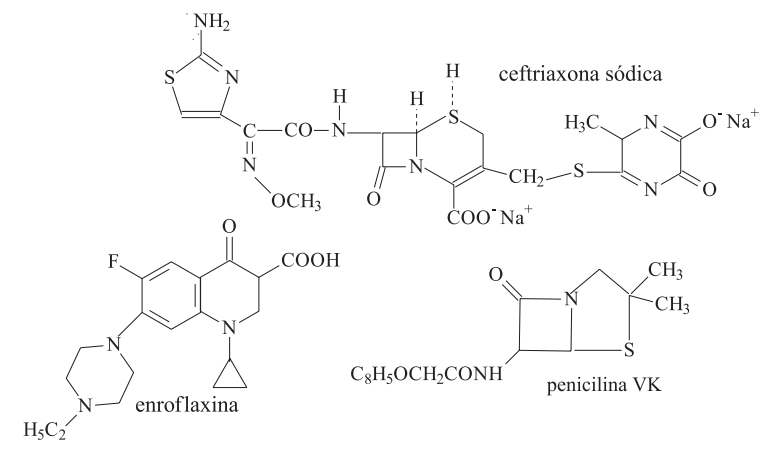

Figura 4. Estrutura química de alguns antibióticos

\section{Pesticidas}

Na síntese de pesticidas são gerados resíduos que contêm inúmeros compostos tóxicos e não-biogradáveis que permanecem no ambiente ainda que submetidos aos processos de tratamento de rejeitos convencionais ${ }^{49}$.

Demonstrou-se que o ozônio é capaz de reagir com inseticidas organofosforados, pesticidas organoclorados e organonitrogenados, sendo efetivo na degradação destes, sobretudo quando a reação é conduzida em meio alaclino. A oxidação por ozônio de um efluente contendo clorobenzenos em concentrações de até $5 \mathrm{mg} \mathrm{L}^{-1}$ foi estudada por Cortes et al..$^{50}$. No entanto, são necessários mais estudos para avaliar a habilidade do ozônio na redução da toxicidade destes compostos, visto que nos ensaios de ozonização realizados por Ormad et al., os subprodutos formados foram mais tóxicos que os originalmente presentes ${ }^{49}$. A produção de dicofol e tetradifon (Figura 5), por exemplo, gera um efluente no qual estão presentes muitos compostos organoclorados como clorobenzenos, DDTs (dicloro-difeniltricloroetano) e seus metabólitos, clorobenzaldeído, ácido clorobenzóico, entre outros, reconhecidamente tóxicos e recalcitrantes ${ }^{49}$.

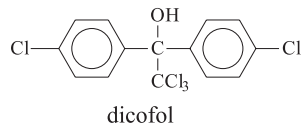

dicofol

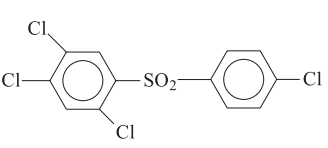

tetradifon
Figura 5. Estruturas químicas do dicofol e tetradifon

Chiron et al. $^{51}$ estudaram a degradação de pirimifosmetil, um pesticida organofosforado, pela utilização de $\mathrm{TiO}_{2} / \mathrm{UV}$ e ozônio para efeito de comparação. A degradação do composto e a formação de subprodutos foram analisadas por técnicas de COT e CG/MS (cromatografia gasosa acoplada ao espectrômetro de massa). A degradação do composto por ozonização mostrou-se mais rápida, com redução de $90 \%$ do valor inicial de COT em $1 \mathrm{~h}$ de tratamento. A ozonização foi considerada a técnica mais eficiente para eliminação de diferentes pesticidas em águas residuais, quando comparada com outros Processos Oxidativos Avançados (Foto-Fenton e Fotocatálise com $\left.\mathrm{TiO}_{2}\right)^{51}$.

\section{Efluente queijeiro}

Um rejeito considerado extremamente problemático é o subproduto da fabricação de queijos, o soro de queijo ${ }^{52-54}$. De acordo com ABIQ (Associação Brasileira das Indústrias Produtoras de Queijos), a produção anual de queijo no Brasil é de aproximadamente 350.000 toneladas por ano, gerando 3,5 milhões de t de soro de queijo. Este resíduo é caracterizado principalmente pela elevada carga orgânica (DQO de 50000-80000 $\mathrm{mg} \mathrm{L}^{-1}$ e DBO de 30000-60000 $\mathrm{mg} \mathrm{L}^{-1}$ ) e a imensa quan- tidade de efluentes gerados (cerca de 3,7 bilhões de litros só no ano de 2002) $)^{54}$.

Em geral, as indústrias produtoras de queijo são de pequeno porte, não possuindo meios econômicos ou tecnologia disponível para o reprocessamento deste resíduo, que poderia ser transformado em produtos alimentícios de maior valor agregado ${ }^{55}$.

Atualmente, apenas $50 \%$ da produção mundial de soro de queijo gerado é tratado ou transformado em produtos alimentícios. O restante é disposto em rios, lagos, ou outros corpos de água, causando grave impacto ambiental ${ }^{53}$. Processos biológicos, tais como lodo ativado são geralmente utilizados em tratamentos deste tipo de resíduo, no entanto, devido à elevada carga orgânica do efluente, o sistema de tratamento é bastante susceptível a problemas de intumescimento do lodo ("bulking") 52 .

A eficiência do processo de ozonização foi estudada por Almeida e Durán ${ }^{54}$ no tratamento deste efluente, com o objetivo de reduzir parte da carga orgânica. Foram estudadas diferentes doses (7 e $14 \mathrm{mg} \mathrm{L}^{-1}$ ) de ozônio, bem como diferentes valores de $\mathrm{pH}$ inicial do efluente (4 e 10), com intuito de otimizar as condições experimentais. Foi demonstrado que o processo de ozonização, tanto por via direta como indireta, não é eficiente na remoção da carga orgânica do soro, em nenhuma das condições estudadas ${ }^{54}$. Como o principal problema ambiental associado ao efluente queijeiro é a elevada carga orgânica, o processo de ozonização não se apresenta como uma alternativa viável de tratamento. Processos biológicos combinados parecem ser mais adequados para a remediação deste tipo de efluente, uma vez que possibilitam a remoção gradual da carga orgânica presente.

\section{APLICAÇÃO DE OZÔNIO EM EFLUENTES INDUSTRIAIS: TECNOLOGIAS EMERGENTES}

Dentre as possíveis variações do processo de ozonização aplicado à remoção de contaminantes específicos, bem como ao tratamento de efluentes industriais, a ozonização catalítica (utilizando metais) e a fotocatálise heterogênea-ozônio (utilizando nanopartículas do semicondutor) constituem as mais recentes variações do processo de ozonização encontradas na literatura.

A ozonização catalítica implica na utilização de íons metálicos como catalisadores do processo, com o objetivo de aumentar a eficiência das reações de ozonização, principalmente na redução da carga orgânica com consumo de ozônio inferior ao da ozonização convencional ${ }^{12}$. Dados da literatura indicam que a presença de íons metálicos aumenta a formação de radical hidroxila, o que possibilita um aumento na decomposição ou mineralização de substâncias orgânicas presentes. Dentre os íons metálicos utilizados $\left(\mathrm{Mn}^{+2}, \mathrm{Fe}^{+2}, \mathrm{Cu}^{+2}\right.$, $\mathrm{Zn}^{+2}$ ), o $\mathrm{Mn}^{+2}$ apresenta resultados mais significativos. Um exemplo de aplicação é na mineralização de uma solução de 2-clorofenol ( $\left.0,778 \mathrm{mmol} \mathrm{L}^{-1}\right)$, cuja remoção de COT aumentou de 11 para $38 \%$ com a adição de $1 \mathrm{mg} \mathrm{L}^{-1}$ de $\mathrm{MnSO}_{4}$ após 20 min de ozonizaçãa ${ }^{56}$.

Arslan et al ${ }^{13}$ compararam a eficiência da ozonização catalítica $\left(\mathrm{O}_{3} / \mathrm{Mn}^{+2} / \mathrm{pH} 3\right)$ e $\mathrm{O}_{3} / \mathrm{H}_{2} \mathrm{O}_{2} / \mathrm{pH} 7,5$ na descoloração e remoção de DQO de um efluente têxtil sintético, preparado com uma mistura de seis corantes reativos, sendo o $\mathrm{pH}$ deste efluente sintético igual a 10,9. Experimentos preliminares de otimização do processo foram realizados para indicar o $\mathrm{pH}$ e as doses ideais de $\mathrm{H}_{2} \mathrm{O}_{2}$ e $\mathrm{Mn}^{+2}$. A cinética de descoloração para o processo $\mathrm{O}_{3} / \mathrm{Mn}^{+2} / \mathrm{pH} 3$ foi maior, embora a completa descoloração tenha sido atingida após 30 min de tratamento, para ambos os processos. A remoção de COT não foi significativa, sendo as porcentagens de remoção encontradas iguais a 11 e $6 \%$ para os processos $\mathrm{O}_{3} / \mathrm{H}_{2} \mathrm{O}_{2} / \mathrm{pH}$ 7,5 e ozonização catalítica, respectivamente. $\mathrm{O}$ efeito da adição do metal como catalisador do processo pode ter sido ocultado pela complexidade da matriz estudada, resultando em vários efeitos competitivos pelos radicais hidroxilas formados ${ }^{13}$. 
Dentro do contexto das novas tecnologias para a degradação de poluentes, a fotocatálise heterogênea apresenta-se bastante promissora, devido principalmente à utilização de nanopartículas do semicondutor. O termo nanopartículas é genérico, sendo usado de acordo com o tamanho da partícula a que está se referindo. Partículas com tamanho menor que $1 \mu \mathrm{m}$ são denominadas nanopartículas, enquanto que as partículas maiores são micropartículas ${ }^{57}$. De maneira bastante simplificada, a fotocatálise heterogênea consiste na formação de sítios oxidantes e redutores na superfície do semicondutor, mediados pela luz. Estes sítios são capazes de catalisar reações químicas, que podem ser utilizadas no tratamento de efluentes industriais ${ }^{4}$. Um estudo empregando nanopartículas de $\mathrm{TiO}_{2} / \mathrm{UV} / \mathrm{O}_{3}$ mostrou que tal combinação apresentou um aumento considerável na remoção de COT na degradação de catecol, quando comparado aos processos $\mathrm{TiO}_{2} / \mathrm{UV}, \mathrm{UV} / \mathrm{O}_{3}$ e somente ozonização ${ }^{58}$. O fato é que as partículas apresentam dimensões bastante reduzidas, inferior ao comprimento de onda da luz incidente, o que resulta num aproveitamento total da luz incidente para a produção dos sítios catalíticos.

Segundo Chitose et al. ${ }^{14}$, as nanopartículas de $\mathrm{TiO}_{2}(30 \mathrm{~nm}$ Nippon Aerosil Corp.) possuem grandes áreas superficiais e, considerando que as reações catalíticas ocorrem na superfície do catalisador, tal característica pode acelerar essas reações aumentando a eficiência do tratamento, o que permite inferir significativa remoção de COT na degradação de fenol, empregando $\mathrm{TiO}_{2} / \mathrm{UV}$.

Fan et al. ${ }^{59}$ utilizaram nanopartículas de $\mathrm{TiO}_{2}$ (P-25, Degussa) para a fotodegradação do metilorange, composto utilizado como modelo de poluente. Observaram que o processo fotocatalítico utilizando P-25 foi bastante eficiente na descoloração e degradação do composto modelo, gerando moléculas menores, como $\mathrm{CO}_{2} \mathrm{e}_{2} \mathrm{O}_{2}$.

De fato, a área superficial pode influenciar na atividade fotocatalítica do semicondutor, no entanto, não existe necessariamente uma dependência direta entre estes dois fatores. Rachel et al.$^{60}$ estudaram a eficiência do semicondutor $\mathrm{TiO}_{2}$ com diferentes áreas superficiais na eliminação de ácidos sulfônicos aromáticos. Dentre os semicondutores utilizados, o P-25 da Degussa (70\% anatase-30\% rutilo; $55 \mathrm{~m}^{2} \mathrm{~g}^{-1}$ ) foi mais eficiente para a degradação do 3-ácido nitrobenzeno sulfônico. Entretanto, para o substrato 2,5 ácido dissulfônico anilínico, a maior eficiência de degradação foi obtida sobre o catalisador PC 500 da Millenium (anatase; $250 \mathrm{~m}^{2} \mathrm{~g}^{-1}$ ). Desta forma, a eficiência de um processo fotocatalítico depende também do tipo de substrato utilizado.

Sun et al. ${ }^{61}$ compararam a eficiência fotocatalítica de nanopartículas de $\mathrm{TiO}_{2}$, com dimensões inferiores a $7 \mathrm{~nm}$, na degradação de fenol. A atividade fotocatalítica neste caso foi dependente da estrutura morfológica da nanopartícula, sendo a forma anatase mais eficiente.

\section{APLICAÇÃO DE OZÔNIO EM EFLUENTES INDUSTRIAIS: PROCESSO COMBINADO QUÍMICO X BIOLÓGICO}

Devido ao fato de que diversos processos de tratamento de efluentes industriais freqüentemente apresentam deficiências quando aplicados isoladamente, como a ineficiência de descoloração do efluente papeleiro por processos biológicos e a remoção de COT pelos processos de ozonização, o estudo de processos combinados torna-se uma das alternativas mais viáveis para a redução do impacto ambiental de muitos resíduos industriais. Teoricamente, a elaboração de rotinas de tratamento fundamentadas na combinação das melhores propriedades de cada tipo de processo é uma das alternativas para enfrentar este crítico problema.

Os tratamentos químicos podem ser utilizados para aumentar a biodegradabilidade de compostos recalcitrantes, diminuindo o tempo de tratamento dos processos biológicos tradicionais. No caso do efluente papeleiro, o ozônio é capaz de remover significativamente a cor deste efluente em tempo reduzido de tratamento, no entanto, a remoção da DQO não é satisfatória. Por outro lado, o tratamento biológico, como lodos ativados, apresenta elevada capacidade de remoção de DQO e DBO, mas baixa eficiência para descoloração e remoção de compostos refratários. Desta forma, a combinação destes processos é uma das alternativas mais viáveis para a redução do impacto ambiental deste e de outros efluentes como, por exemplo, o têxtil.

O tratamento combinado ozônio-lodo ativado foi aplicado ao efluente papeleiro, mostrando capacidade em degradar eficientemente a lignina ${ }^{17}$. A ozonização em condições alcalinas ( $\mathrm{pH}$ 12) aumenta a degradação da lignina e a formação de ácidos orgânicos, tais como ácido maleico e oxálico, resultantes da quebra de compostos aromáticos presentes na lignina. Assim, um aumento da concentração de ácidos orgânicos indica maior razão de degradação da lignina. Além disso, ácidos orgânicos podem ser degradados eficientemente pelo processo de lodo ativado ${ }^{17}$.

Beltran et al. ${ }^{62}$ estudaram o processo combinado, lodo ativado ozonização, no tratamento do efluente proveniente de uma destilaria. O processo de lodo ativado foi capaz de reduzir até $95 \%$ da DQO e $82 \%$ da DBO. Entretanto, a concentração de compostos polifenólicos e a absorbância a $254 \mathrm{~nm}$ não puderam ser reduzidas mais que 35 e $25 \%$, respectivamente. Com a aplicação do processo combinado, a eficiência do sistema aumentou, principalmente em termos de remoção de polifenóis e absorbância a $254 \mathrm{~nm}$, sendo, portanto, a ozonização bastante apropriada para auxiliar o processo biológico no tratamento deste efluente.

Zenaitis et al. ${ }^{63}$ avaliaram o uso do ozônio como pré e pós-tratamento biológico (lodo ativado) para os efluentes de madeira. Durante o pré-tratamento com ozônio, a concentração de taninos - ligninas e a toxicidade aguda $\left(\right.$ microtox $\left.^{\circledR}\right)$ foi rapidamente reduzida em 70 e $71 \%$, respectivamente. No entanto, a pré ozonização, promoveu uma redução da DBO e da DQO inferior a 10\%. O efluente tratado biologicamente, submetido ao processo de ozonização (pós-tratamento), demonstrou aumento de DBO em $38 \%$, devido à conversão da matéria orgânica não biodegradável (expressa como parte da DQO determinada), o que significa um aumento da biodegradabilidade do efluente.

O mesmo tratamento foi aplicado por Orhon et al. ${ }^{64}$ ao efluente têxtil, com o objetivo de otimizar a redução de DQO e cor. Como pré-tratamento, em 15 min de ozonização observaram eficiência de remoção de $85 \%$ de cor mas, somente $19 \%$ de remoção da DQO do efluente. Como pós-tratamento, a ozonização foi muito mais efetiva na quebra de compostos orgânicos refratários, atingindo uma completa remoção da cor. Do ponto de vista econômico, o efeito polidor da ozonização é bastante atrativa, uma vez que reduz até $50 \%$ o consumo de ozônio ${ }^{64}$.

Uma variação do processo combinado, ozônio-biotratamento, foi estudada por Nishijima et al. ${ }^{27}$.O chamado tratamento multi-estágio ozônio-biológico consiste numa ozonização prévia, seguida pelo tratamento biológico, sendo esta seqüência repetida mais uma vez. Maior eficiência de remoção de COD (carbono orgânico dissolvido) foi obtida quando comparada ao processo de um único estágio, para um mesmo tempo de ozonização. Isto se deve ao fato de que os compostos refratários foram transformados em outros, passíveis de biodegradação, sendo eliminados pelo processo biológico, o que implica na redução de compostos competitivos pelo ozônio na próxima etapa de ozonização ${ }^{27}$.

O pré-tratamento com ozônio é tecnicamente viável para a remoção de compostos recalcitrantes, presentes em inúmeros tipos de efluentes. Entretanto, é importante salientar que, para cada tipo de efluente, a natureza dos compostos presentes, bem como dos grupos substituintes, irá determinar o consumo de ozônio, o aumento do 
grau de degradabilidade e a possível remoção (ou aumento) da toxicidade ${ }^{2}$

\section{CONCLUSÕES}

Os avanços das tecnologias alternativas para a remediação de efluentes, dentre elas os processos oxidativos avançados, vêm contribuindo para o desenvolvimento do controle da poluição ambiental.

De modo geral, o processo de ozonização apresenta-se eficiente, principalmente, na descoloração, remoção de compostos refratários e aumento da biodegradabilidade de diferentes tipos de efluente, inclusive os que foram discutidos neste trabalho. Apenas para o efluente queijeiro a aplicação do processo de ozonização não é recomendável, devido à incapacidade do processo em remover a carga orgânica, principal problema associado a este efluente.

A eficiência do processo de ozonização depende de diversos fatores, como $\mathrm{pH}$ (que determinará o oxidante predominante $\mathrm{O}_{3} \mathrm{ou}$ radical hidroxila), tipo de contaminante, complexidade da matriz, etc. Entretanto, por si só o ozônio não é capaz de prover um elevado grau de mineralização do efluente, o que é mostrado pelas pequenas taxas de remoção de COT apresentadas, mesmo utilizando-se outros POAs associados ao ozônio ${ }^{10}$. No entanto, é indiscutível que ocorre alguma alteração na estrutura química dos compostos, uma vez que se observa aumento de biodegradabilidade.

O grande desafio para tornar a ozonização uma tecnologia de remediação mais abrangente é atingir maiores taxas de mineralização, obtendo-se alta eficiência de remoção da carga orgânica do efluente. Com este propósito, a ozonização catalítica, a nanocatálise heteogênea, bem como a combinação com processos biológicos, são apresentados na literatura como a tendência atual na aplicação de ozônio na remediação de efluentes.

\section{AGRADECIMENTOS}

Os autores agradecem a FAPESP pelo apoio financeiro.

\section{REFERÊNCIAS}

1. Peralta-Zamora, P.; Espósito, E.; Reyes, J.; Durán, N.; Quim. Nova 1997, 20, 186.

2. Alvares, A. B. C.; Diaper, C.; Parsons, S. A.; Environ. Technol. 2001, 22, 409.

3. Masten, S. J.; Davies, S. H. R.; Environ. Sci. Technol. 1994, 28, 181A.

4. Freire, R. S.; Pelegrini, R.; Kubota, L. T.; Durán, N.; Quim. Nova 2000, $23,504$.

5. Kunz, A.; Freire, R. S.; Rohwedder, J. J. R.; Durán, N.; Mansilla, H.; Rodriguez, J.; Quim. Nova 1999, 22, 425.

6. Robinson, T.; McMullan, G.; Marchant, R; Nigam, P.; Bioresour. Technol. 2001, 77, 247.

7. Balakrishnan, P. A.; Arunagiri, A.; Rao, P. G.; J. Electrostat. 2002, $56,77$.

8. Lin, S. H.; Yeh, K. L.; Chem. Eng. 1993, 112.

9. von Gurten, U.; Water Res. 2003, 37, 1443.

10. Freire, R. S.; Kubota, L.T.; Duran, N.; Environ. Technol. 2001, 22, 897.

11. Sunder, M.; Hempel, D. C.; Water Res. 1997, 31, 33.

12. Bacioglu, I. A.; Arslan, I.; Water Sci. Technol. 2001, 43, 221.

13. Arslan, I.; Balcioglu, I. A.; Tuhkanen, T.; Water Sci. Technol. 2000, 42, 13.

14. Chitose, N.; Ueta, S.; Seino, S.; Yamamoto, T. A.; Chemosphere 2003, 50, 1007.

15. Anônimo; Celulosa y Papel (Chile) 1999, 30.

16. Mansilla, H. D.; Lizama, C.; Gutarra, A.; Rodríguez, J.; Ciencia y Tecnología para el Desarrollo-CYTED 2001, 85, 294.

17. Nakamura, Y.; Sawada, T.; Kobayashi, F.; Godliving, M.; Water Sci. Technol. 1997, 35, 277.

18. Archibald, F. S.; Valeanu, L.; Leichtle, G.; Guilbault, B.; J. Water Qual. Res. 1998, 33, 347.
19. Yeber, M. C.; Rodriguez, J.; Freer, J.; Baeza, J.; Durán, N.; Mansilla, H. D.; Chemosphere 1999, 39, 1679.

20. Helble, A.; Schlayer, W.; Liechti, P. A.; Jenny, R.; Mobius, C. H.; Water Sci. Technol. 1999, 40, 343.

21. Freire, R. S.; Kunz, A.; Durán, N.; Environ. Technol. 2000, 21, 717.

22. Soares, C. H. L.; Duran, N.; Environ. Technol. 1998, 19, 883.

23. Correa, J.; Dominguez, V. M.; Martinez, M.; Vidal, G.; Environ. Int. 2003, $29,459$.

24. Santos, C. P.; Reis, I. N.; Moreira, J. E. B.; Brasileiro, L. B.; Química Nova na Escola 2001, nํㅜㄴ. 3.

25. Evans, T.; Sweet, B.; Manoluscu, D.; Mason, J.; Pulp Paper Canada 1995, 96,60 .

26. Thompson, G.; Swain, J.; Kay, M.; Forster, C. F.; Bioresour. Technol. 2001, $77,275$.

27. Nishijima, W.; Fahmi, H.; Mukaidani, T.; Okada, M.; Water Res. 2003, 37, 150.

28. Zhou, H.; Smith, D. W.; Water Sci. Technol. 1997, 35, 251.

29. Espluglas, S.; Gimenez, J.; Contreras, S.; Pascual, E.; Rodrigueez, M.; Water Res. 2002, 36, 1034.

30. Guimarães, J. R.; Dissertação de Mestrado, Universidade Estadual de Campinas, Brasil, 1990.

31. Hostachy, J. C.; Lenon, G.; Pisicchio, J. L.; Coste, C.; Legay, C.; Water Sci. Technol. 1997, 35, 261.

32. Sponza, D. T.; Ecotoxicol. Environ. Saf. 2003, 54, 74.

33. Assalin, M. R.; Rosa, M. A.; Durán, N.; Ozone: Sci. Eng. 2004, $26,317$.

34. Rosa, M. A.; Assalin, M. R.; Durán, N.; Resumos do VI Simpósio Ítalo Brasileiro de Engenharia Sanitária e Ambiental, Vitória, Brasil, 2002.

35. Perez, M.; Torrades, F.; Domenech, X.; Peral, J.; J. Chem. Technol. Biotechnol. 2002, 77, 525.

36. Kunz, A.; Mansilla, H.; Duran, N.; Environ. Technol. 2002, 23, 911.

37. Guaratini, C. C. I.; Zanoni, M. V. B.; Quim. Nova 2000, 23, 71

38. Kunz, A.; Peralta-Zamora, P.; Moraes, S. G.; Durán, N.; Quim. Nova 2002, 25,78 .

39. Ciardelli, G.; Ranieri, N.; Water Res. 2001, 35, 567.

40. Vandivere, P. C.; Bianchi, R.; Verstraete, W.; J. Chem. Technol. Biotechnol. 1998, 72, 289.

41. Sevimli, M. F.; Kinaci, C.; Water Sci. Technol. 2002, 45, 279.

42. Sevimli, M. F.; Sarikaya, H. Z.; J. Chem. Technol. Biotechnol. 2002, 77, 842.

43. Chu, W.; Chi-Wai, M. A.; Water Res. 2000, 34, 3153.

44. Kharisheh, M. A. M.; Color. Technol. 2003, 119, 24.

45. Balcioglu, I. A.; Ötker, M.; Chemosphere 2003, 50, 85.

46. Arslan-Alaton, I.; Balcioglu, A.; Arch. Environ. Contam. Toxicol. 2002, 43, 425 .

47. Ternes, T. A.; Stüber, J.; Herrmann, N.; McDowell, D.; Ried, A.; Kanmpmaann, M.; Teiser, B.; Water Res. 2003, 37, 1976.

48. Zwiener, C.; Frimmel, F. H.; Water Res. 2000, 34, 1881.

49. Ormad, P.; Cortés, S.; Puig, A.; Ovelleiro, J. L.; Water Res. 1997, 31, 2387.

50. Cortes, S.; Sarasa, J.; Ormad, P.; Gracia, R.; Ovelleiro, J. L.; Ozone: Sci. Eng. 2000, 22, 415.

51. Chiron, S.; Rodrigues, A.; Fernadez-Alba, A.; J. Chromatogr., A 1998, 832, 97.

52. Cristiani-Urbina, E.; Netzahuatl-Muñoz, A. R.; Manriquez-Rojas, F. J.; Juárez-Ramíres, C.; Ruiz-Ordaz, N.; Galíndez-Mayer, J.; Process Biochem. 2000, 35, 649 .

53. Gonzáles-Sizo, M. I.; Bioresour. Technol. 1996, 57, 1.

54. Almeida, E.; Duran, N.; Resumos I Fórum das Universidades Públicas Paulistas: Ciência e Tecnologia em Resíduos, São Pedro, Brasil, 2003.

55. Révillion, J. P.; Brandelli, A.; Ayub, M. A. Z; Ciênc. Tecnol. Aliment. 2000, 20,1 .

56. Ni, C. H.; Chen, J. N.; Yang, Y.; Water Sci. Technol. 2002, 47, 77.

57. h t t p : / / l q e s.i q m. u n i c a m p.b r/i mage s/ vivencia_lqes_monografias_marcelo_nanoesferas.pdf, acessada em Novembro $200 \overline{3}$.

58. Li, L. S.; Zhu, W. P.; Zhang, P. Y.; Chen, Z. Y.; Chen, L.; Chin. J. Catal. 2003, 24, 163.

59. Fan, Q. P.; Wang, X.; Li, Y. D.; Chin. J. Inorg. Chem. 2003, 19, 521.

60. Rachel, A.; Sarakha, M.; Subahmanyam, M.; Boule, P.; Appl. Catal., B 2002, 37, 293.

61. Sun, J.; Gao, L; Zhang, Q. H.; J. Am. Ceram. Soc. 2003, 86, 1677.

62. Beltran, F. J.; Alvarez, P. M.; Rodriguez, E. M.; Garcia-Araya, J. F.; Rivas, J.; Biotechnol. Progr. 2001, 17, 462.

63. Zenatais, M. G.; Sandhu, H.; Duff, S. J. B.; Water Res. 2002, 36, 2053.

64. Orhon, D.; Dulkadiroglu, H.; Dogruel, S.; Kabdasli, I.; Sozen, S.; Babuna, F. G.; Water Sci. Technol. 2002, 45, 305. 